\title{
Carlos Mata Induráin, Antonio Sánchez Jiménez y Martina Vinatea (eds.), La escritura del territorio americano, New York, Instituto de Estudios Aurisecu- lares (IDEA), 2019, 252 pp. ISBN: 978-1-938795-61-9
}

\section{Daniele Arciello}

https://orcid.org/0000-0003-0754-6527

Universidad de León

ESPAÑA

darc@unileon.es

[Hipogrifo, (issn: 2328-1308), 9.2, 2021, pp. 1103-1107]

Recibido: 05-11-2021 / Aceptado: 18-11-2021

DOI: http://dx.doi.org/10.13035/H.2021.09.02.71

El universo de la cultura hispánica, especialmente la que abarca los denominados Siglos de Oro, se caracteriza por una complejidad de temas y estilos asombrosa. Justamente por ello, es preciso que iniciativas como la que promociona la Universidad de Navarra, que consiste en dar a la imprenta volúmenes que abordan dicha complejidad desde una gran variedad de enfoques y propuestas de análisis, reciban una merecida visibilidad académica. En efecto, cada vez que un lector decida adentrarse en las páginas que ofrece la colección «Batihoja», sabe que va a encontrarse con aportaciones de calidad. El nutrido número de volúmenes ha ido contribuyendo a dilucidar numerosos enigmas y cuestiones irresolutas. En este sentido, La escritura del territorio americano cumple con la misión de brindar unas investigaciones que ayudan a encaminar a todo interesado hacia los conocimientos relativos al acto de escribir sobre y en el Nuevo Mundo.

La acción creadora de los autores de España e Hispanoamérica es tan importante que el prologuista del volumen, Antonio Sánchez Jiménez, no duda en poner en énfasis «cómo los europeos inventaron América o (y quizás aquí está el desarrollo más importante de los últimos años) cómo los americanos adoptaron y modificaron esta invención para potenciar sus propios intereses» (p. 9). Este dato 
nos sirve para reflexionar sobre la relevancia de las opiniones que se desarrollaron en las diferentes fases cronológicas de la historia de América y Europa y que, al parecer, están más vivas que nunca hoy en día. Estas páginas preliminares, que tan acertadamente redactó el profesor de Neuchâtel, ilustran el carácter heterogéneo de los trabajos que vertebran el libro, aunque a la vez resaltan su homogeneidad argumentativa, ya que todos mantienen un estrecho vínculo con la producción histórica, literaria y cultural de y sobre América.

En este monográfico, el primer ejemplo de aquello que Antonio Sánchez Jiménez define en Preliminares como «quimeras europeas» (p. 9) es la plasmación de un entorno fabuloso que cobra vida no por la experiencia sensorial, sino por una visión plenamente subjetiva que dos representantes emblemáticos del imaginario europeo generan: el cervantino Don Quijote y Cristóbal Colón. Así nos lo expone Jordi Aladro en «América quijotizada en los Diarios de Cristóbal Colón» (pp. 15-26). El autor va destacando los puntos en común entre ambas figuras a lo largo de su investigación: la fe en las propias convicciones, el poder de su fantasía y, finalmente, las lecturas que vehiculizan su imaginación.

Pasamos de los territorios de la imaginación a lugares geográficos con la contribución de César Belan. En su capítulo «Un espacio libre de bandidos: topografía delictiva de la ciudad de Arequipa (1780-1824)» (pp. 27-41), el autor propone un análisis de zonas urbanas arequipeñas entre los siglos XVIII y XIX en relación con la criminalidad. Demuestra que ya desde el XVII muchos escritores estudiaban la conexión entre ambiente y delitos; así, hace hincapié en la vida criminosa de la zona periférica de Arequipa. Alcohol, mancebía y hacinamiento en los barrios más pobres eran causa de riñas y homicidios. El autor concluye que aquellos espacios suponían una constante amenaza a la tranquilidad pública y privada.

De esperanzas frustradas nos habla José Antonio Crespo-Francés en «Sobre la importancia estratégica de la Florida: la quimera del paso hacia la China» (pp. 43-64), al mencionar los intentos de encontrar un pasaje que uniese los océanos Atlántico y Pacífico, que se debieron a un plan de exploración ideado por Cortés para evitar pasar por zonas plagadas de piratas. El autor nos revela que el esfuerzo de localizar un paso que conectase sendos océanos fracasó por ignorar la enormidad de las áreas del continente que aún no se habían visitado. Lo que enriquece su trabajo son las notas explicativas de las fuentes que cita textualmente, los muchos mapas con indicaciones de elaboración propia y los conocimientos no solo geográficos, sino también los que se relacionan con los cambios climáticos de los siglos XVI y XVII.

Con elegancia nos adentramos en los resortes filosóficos peruanos, gracias a las reflexiones de Jean Christian Egoávil sobre la obra de un limeño del XVI. De hecho, «Las condiciones para el desarrollo de la filosofía virreinal en el Perú como fundamento del pensamiento peruano. El caso de la Logica Via Scoti (Lima, 1610) de Jerónimo de Valera (1568-1625)» (pp. 65-92) es un ensayo de carácter apologético cuyo objetivo es probar la existencia de un desarrollo filosófico en época virreinal que se dio sin ataduras directas con el pensamiento metropolitano. Egoávil lo expresa claramente: «Es imprescindible superar la resistencia del prejuicio con 
respecto al período virreinal como una época de inferioridad cultural y filosófica con una dependencia de Europa, como si los pensadores americanos hubiesen sido simplemente cajas de resonancia del pensamiento europeo» (p. 67). De esta manera, pues, incide en la lamentable conexión entre estereotipos pasados y lugares comunes actuales, procurando refutarlos.

De tema afín a un trabajo de Mariela Insúa, que se publicó en otro volumen de la colección («Algunas calas en la risa y el llanto. Demócrito y Heráclito, del Siglo de Oro a Fernández de Lizardi», en Barroco de ambos mundos. Miradas desde Puebla, ed. Ignacio Arellano y Robin Ann Rice, New York, IDEA, 2019, pp. 137-156), es el de Celsa Carmen García Valdés. «Códigos de la risa en los festejos teatrales de sor Juana Inés de la Cruz» (pp. 93-108) también ahonda en la polisemia humorística de dos figuras clásicas muy relevantes en el ámbito de la cultura barroca: Demócrito y Heráclito. En este caso, el argumento se enfoca en el teatro de la celebérrima Sor Juana. Tras subrayar la presencia de lo cómico en muchas creaciones de la monja, García Valdés nos recuerda que la escritura literaria del siglo XVII -en especial modo, los criados como portavoces de cordura y crítica social frente a los dislates de los cortesanos - se tiene en gran consideración en las piezas de la décima musa. La autora concluye afirmando que palabras y gestos de la servidumbre constituyen el componente esencial de la ironía teatral de Sor Juana.

En lo relativo a la defensa de la cultura virreinal, el estudio de Arnulfo Herrera es más incisivo que el de Egoávil («La rebelión pasiva de los criollos y la forja de la patria», pp. 109-125). Centrándose en la producción criolla y española de tratados, discursos y cartas, Herrera comenta con viveza la diatriba en torno a la supuesta inferioridad intelectual criolla que factores climáticos y humorales causarían. Se cotejan textos de diferentes procedencias y estilos, priorizando en términos de calidad las obras Theatro mexicano y Biblioteca mexicana, en ocasiones utilizando una terminología bastante llamativa, como la frase «desahogos de canallas enanos» (p. 124) para referirse a lo que escribieron autores que para el investigador no estarían a la altura de otras.

Una prueba concluyente de que un ser fantástico puede traspasar los límites del folklore local y alcanzar las orillas de otros continentes, viajando por el espacio y el tiempo, la hallamos en «Derivas hispánicas del pez Nicolás» (pp. 127-140), de Mariela Insúa. Enlazando las presuntas localizaciones en Sicilia del legendario Colapesce con elaboraciones e interpretaciones hispanas, se esboza una sugerente ruta por lugares y épocas que han atestiguado la pervivencia de este mito en variadas fuentes histórico-literarias, desde la Edad Media hasta los siglos XX y XXI. Se pueden rastrear sus huellas no solo en la prosa contemporánea, sino también en las más recientes películas. A la luz de ello, Insúa no deja de acentuar la heterogeneidad de las plasmaciones y adaptaciones del mito en cuestión, que aún sigue protagonizando cuentos, películas y anécdotas.

Por su escasa bibliografía, podemos reputar de descriptiva-divulgativa, más que científica, la aportación de Blanca López de Mariscal, cuyo título es «El Pacífico en el viaje de fray Diego de Ocaña por la América del Sur (1599-1600)» (pp. 141-155). No es casual que la autora lo aclare desde el principio, pues propone hacer una «revi- 
sión de una pequeña parte» (p. 141) del itinerario emprendido por el evangelizador español. Se trata de una descripción evocativa de las exploraciones, en sintonía con el interés que la obra examinada despierta, tanto para el lector moderno como el de antaño. La sugestión que genera este trabajo se intensifica por la comparación de dos acuarelas, junto con un buen conjunto de notas esclarecedoras y citas textuales.

De las manifestaciones prosísticas y visuales nos movemos hacia representaciones de talante climático y paisajístico con Camila Mardones Bravo. Su trabajo tematiza la carga moral y simbólica que las experiencias de evangelización en tierras hostiles acarreaban. En particular, se evidencia la contraposición entre la visión edénica asociada con regiones placenteras americanas y las connotaciones negativas del altiplano entre Perú y Bolivia. En «Altiplano alegórico. Clima y paisaje en los Murales de Santiago de Curahuara de Carangas, Audiencia de Charcas» (pp. 157-173), pues, se traza un esquema de factores que determinaron una visión poco positiva de dicho territorio, considerando cómo aquel juicio recibió mucha influencia por parte de religiosos españoles que vivieron allí. Todo ello confluye en las figuraciones alegóricas que se observan en los murales de la zona y que, según lo que nos explica Mardones Bravo, son un ejemplo eficaz de cómo una ideología procedente de otras perspectivas espirituales puede afectar a toda una comunidad.

También en el estudio comparativo de Laura Yadira Munguía Ochoa, «Autobiografías femeninas como crónica conventual: el caso de Santa Teresa la Antigua y San Jerónimo de México» (pp. 175-190), la religión juega un papel importante. Esta vez, son las voces femeninas procedentes de conventos novohispanos que estructuran el contenido del texto. Este último nos hace comprender el mérito de las anotaciones que redactaron tres monjas (sor Inés de la Cruz, sor Mariana de la Encarnación y sor Juana Inés de la Cruz), es decir, el habernos facilitado muchos datos no solo sobre la fundación de aquellos conventos, sino también sobre la vida (no siempre) retirada en su interior. Como bien postula Munguía Ochoa, «los conventos eran microcosmos» (p. 189) y con frecuencia investigar sobre ellos es indudablemente gratificante.

A continuación, nos quedamos en el Virreinato de Nueva España con Omar Rodríguez Camarena y «El paraíso en la tierra o la exaltación de las cualidades novohispanas (siglos XVI-XVII)» (pp. 191-207). Al igual que la labor investigativa de Jean Christian Egoávil, se aborda el argumento de la inferioridad americana que algunos autores europeos insinuaron en sus escritos, si bien aquí se sondean las creaciones de quienes se oponían a ello, tanto criollos como europeos. Conforme a la teoría de Rodríguez Camarena, la condición de carencia intelectiva ratificaría la conquista y consiguiente colonización de América por parte de la corona española. Sin embargo, otras vertientes dieron un vuelco a dicha tesis, alegando las cualidades naturales que caracterizaban a los oriundos. La autora menciona a algunas de las eminencias de la época que participaron de la apología de lo americano. Entre otras, destacan Pedro Mártir de Anglería, Cristóbal Colón y el único escritor del barroco novohispano que tal vez pudiese competir con el talento de sor Juana: don Carlos de Sigüenza y Góngora. 
Navegamos ahora por los astros que iluminan la bóveda celeste del Perú. Apreciamos el encuentro entre mitología y examen del zodiaco con órdenes religiosas en "Las celestes esferas de la siempre sabia astrología", la geografía celeste de Ventura Travada en Suelo de Arequipa convertido en Cielo (c. 1752)» (pp. 209-218), de César Félix Sánchez Martínez. Confiriéndole un merecido interés al texto del sacerdote peruano, el investigador resalta el estilo entre lo verosímil y lo retórico de Travada. Sostiene, además, que la adopción de un lenguaje metafórico permitiría una descripción de Arequipa más en consonancia con su valor metafísico, concluyendo que el manejo de aquellos recursos tardobarrocos reflejarían un intento de darle a una región marginal una identidad que se fundamente en lo divino.

Seguimos con las vindicaciones del continente americano, esta vez desde un prisma político-religioso que traduce en palabras e imágenes la voluntad de demostrar lealtad y apego hacia la monarquía. A ello alude «La visión del mundo indígena en las Noticias políticas de Indias de Pedro Ramírez del Águila» (pp. 219-235), de Manuel Sierra Martín. Su punto focal es averiguar cómo se alaba el buen gobierno de los indios y de sus gobernantes en la obra del cronista, quien aprovecha el objetivo principal de su composición, esto es, dar cuenta de la administración material y espiritual de La Plata, para perseguir sus propósitos. Leemos, pues, que el cometido de Ramírez se lleva a cabo con esmero, dando la impresión de que los criollos no pueden quedar en una posición de supeditación en términos de virtudes morales e intelectuales.

Nuestro recorrido llega a su fin con «Las bilocaciones de fray Martín: cartografía sagrada del orbe católico» (pp. 237-252), de Elio Vélez Marquina. Ya había contribuido en «Batihoja» con un capítulo sobre la vida de santos y el criollismo («Transformaciones americanas de la épica culta: hagiografía y posicionamiento criollo en Vida de Santa Rosa», en Viajeros, crónicas de Indias y épica colonial, ed. Mariela Insúa y Jesús Menéndez Pelaéz, New York, IDEA, 2017, pp. 141-194), y de cualidad afín es su contribución en este volumen. Queda patente su intención de dar a conocer los valores patrióticos que se vinculan con la santidad de fray Martín de Porres, tal como observamos en las biografías que le dedicaron. Pese a que ya en otros pasajes de este monográfico se ha debatido sobre los elementos alegóricos y simbólicos que reescriben y reinventan un determinado lugar de América, gracias a las ponderaciones de Vélez Marquina nos percatamos de cómo los mapas y la literatura colaboran para conseguir el mencionado designio.

A la vista de todo lo que se ha comentado sobre las investigaciones que constituyen el andamiaje de La escritura del territorio americano, nos encontramos ante una obra que complementa lo que se ha escudriñado en torno a los procesos de elaboración, reelaboración y neo-elaboración de la idea de América. Multitud de puntos de vista que proceden del arte, la literatura, la historia, la geografía, así como muchos otros, garantizan una visión a veces holística y, en otras ocasiones, pormenorizada del gran anhelo de grandes escritores del pasado por ajustar a sus pretensiones creadoras la realidad que les rodeaba. En definitiva, se van desgranando diversos trabajos que, como nos manifiesta con acierto Antonio Sánchez Jiménez, se desarrollan «con patrones que nos recuerdan la unidad del conjunto» (p. 13). 